\title{
TECHNIQUE FOR PRESERVING COLORED WET SPECIMEN IN ANATOMY MUSEUM
}

\author{
Neelamjit Kaur *1, Rakesh Kumar Agarwal ${ }^{2}$, Seema Khajuria ${ }^{2}$, Harsh ${ }^{2}$, Hemant \\ Saini ${ }^{3}$.
}

${ }^{* 1}$ Professor, Anatomy, Maharishi Markandeshwar Medical College \& Hospital, Kumarhatti, Solan, H.P. India.

${ }^{2}$ Assistant Professor, Anatomy, Maharishi Markandeshwar Medical College \& Hospital, Kumarhatti, Solan, H.P. India.

${ }^{3}$ Senior Demonstrator, Anatomy, Maharishi Markandeshwar Medical College \& Hospital, Kumarhatti, Solan, H.P. India.

\section{ABSTRACT}

Introduction: Anatomy is the science which deals with the structure of human body .Museum in anatomy is a place where bones, models, charts, wet specimen of permanent value are kept and displayed. An attractive and innovative anatomical museum plays a vital role in furthering the interest and educating a medical student.With the help of wet specimen, the students get much information about the normal anatomical parts along with variations in the distribution of nerves, vessels, muscles etc. Once a specimen has undergone fixation it is essential to color and label the specimen in order to ensure better visualization of required structures.

Materials and Methods: The present study was conducted on 50 wet specimens taken from the well embalmed dissected cadavers at the Maharishi Markandeshwar Medical College \& Hospital, Solan, India. We utilized acrylic paints, white enamel paint and transparent nail paint to color arteries, veins, nerves and impressions on the viscera. Then these colored specimen were kept in formalin filled jars.

Results: The painted specimen kept in jars filled with formalin solution remained stable without any visible change in color for a period of two years.

Conclusion: Coloring the important structures and landmarks with acrylic paints, enamel and nail paint is nontoxic and increases durability of specimen.

KEY WORDS: Wet Specimen, Museum, Anatomy, Color, Preserving.

Address for Correspondence: Dr. Neelamjit Kaur, Professor, Anatomy, Maharishi Markandeshwar Medical College \& Hospital, Kumarhatti, Solan, H.P. India. E-Mail: neelamjit@yahoo.co.in

\section{Access this Article online}

\section{Quick Response code}

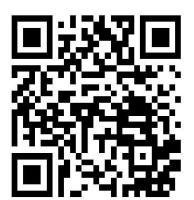

DOI: $10.16965 /$ ijar.2017.192
Web site: International Journal of Anatomy and Research ISSN 2321-4287

www.ijmhr.org/ijar.htm

Received: 20 Mar 2017

Peer Review: 21 Mar 2017

Revised: None
Accepted: 25 Apr 2017

Published (O): 31 May 2017

Published (P): 31 May 2017

\section{INTRODUCTION}

As early as the $19^{\text {th }}$ century anatomy has become a prerequisite for a medical career ,hence private lecturers and hospital practitioners developed anatomical teaching in both England and France at a fast pace [1]. In todays medical educational programs, anatomy is an essential part of the curriculum in the first year of the medical course. The norm of today's medical teaching is 'No Dissection, No Knowledge' [2]. Following dissection of a specimen we can analyze normal anatomy of the given 
structure and the various possible variations in the specimen. Thus developed the process of preservation of specimens and establishing of anatomical museums.

Once the specimens are fixed, it is then mounted and displayed in anatomy museum. A good anatomy museum can provide an in depth learning of the various structures of the body and can further the medical education of the student. The effectiveness of a museum in an educational program is based on the principle that viewing an object is better remembered and recollected than a written or a verbal description [3]. To display the specimen in anatomical museum, coloring and labeling is of utmost importance which helps to support teaching and learning of gross anatomy.

To make the specimens more attractive we utilized mixture of acrylic paint and white enamel paint to color the specimen. Acrylic paints form flexible, non-toxic, versatile but it peels easily when used alone. Enamel is the paint with glossy and opaque finish and provide excellent coverage and color retention. The colored area was further coated with transparent nail paint to ensure the long term preservation. Further labeling of specimen was done by two different methods ie. direct method and color code method. In direct method computerized print paper coated with nail paint was used which remained unaffected in formalin solution. In color code method we fixed label, with name of the structure and the color used on it, on the jars.

Hence a technique has been de-veloped which can be used to color desired structures in wet specimens.

\section{MATERIALS AND METHODS}

The present technique was conducted on 50 wet specimen which belonged to well embalmed dissected cadavers which were obtained from Department of Anatomy, Maharishi Markande shwar Medical College \& Hospital, Kumarhatti, Solan. The materials utilized for the technique were acrylic paints, white synthetic enamel paint, transparent nail paint, painting brushes of different sizes. Turpentine oil was used for cleaning the brushes. Acrylic paints produce filmof great clarity, dry very quickly and form flexible films. Enamel paint provides excellent coverage, color retention, glossy and opaque finish. Transparent nail polish is a type of lacquer applied on human nails and includes nitrocellulose resin, adhesive polymers and solvents[4]. This is cost-effective and non-toxic product and helps in preventing the running of color into the mounting fluid.

The specimens were prepared by fine dissection of the hu-man body parts either fresh or left after dissection by students. When the specimen were prepared they were kept in a room and passive drying was done for one to two days to make the surface of the structures to be colored like vessels, nerves, ligaments muscles, ducts, glands dry enough to apply color. The ves-sels, nerves, etc were raised from the underlying muscles by putting swab of cotton under them which resulted in early drying of structures. The vessels and nerves dry earlier than other structures so color was applied first on them and then on others.

On a glass plate desired shade of color was prepared by mixing acrylic paint colors with white enamel paint. When desired shade was prepared it was painted on the structures. We have used standard color coding for different anatomical structures like red color for artery, blue for vein, and yellow for nerve etc. The acrylic colors when mixed with white enamel color become adherent on the struc-tures. After painting all the structures to be painted, specimen were kept overnight to make the paint dry. Next day the colors were coated with transparent nail paint and kept overnight to dry. Nail polishes are of three varieties gel, base and top coat. We used topcoat clear nail polish for layering. Nail paint further enhance the shine of colors used and increases the binding capacity. Firstly we used only acrylic paints to color the specimens but it was peeling in formalin solution. But mixing with enamel and coating with nail paint provided stability.

Then 25 specimens were labeled by using direct labeling method (Figure 1 and 2 ) and 25 were labeled using the color code method (as shown in Figure 3-6). Labels for direct labeling (Figure 1 and 2) were computerized print paper coated with transparent nail paint on both surfaces and were fixed directly on the specimen with super glue .The color codes used for labeling (Fig 3-6) 
was fixed on the glass jar in which specimen was kept.

The glass jar was filled with mounting fluid which consists of 25 parts by volume of pure glycerine, seventy five parts by volume of distilled water and five parts of formalin. Glycerine in not essential to preserve the specimen, but has a clearing effect on the tissues and improves the optical properties of the fluid, which emphasis the fine structural details. The glycerine and water require very thorough mixing, as the former, being so heavier than the latter, tends to settle out as a separate layer at the bottom of the mixing receptacle [5]. Then the jars were covered with lid, sealed by cello tape and kept in the museum .Over a period of two years, the specimen are still like their original form. Colors are well adherent to the specimen with the same shine and labels in formalin solution have also proved durable. Moreover, the mounting fluid was centrifuged in the pathology laboratory with at $2000 \mathrm{rpm}$ for 10 minutes with the result that no trace of paint was detected and fluid was absolutely clear.

Fig. 1: Relations of the visceral surface of spleen (direct labeling).

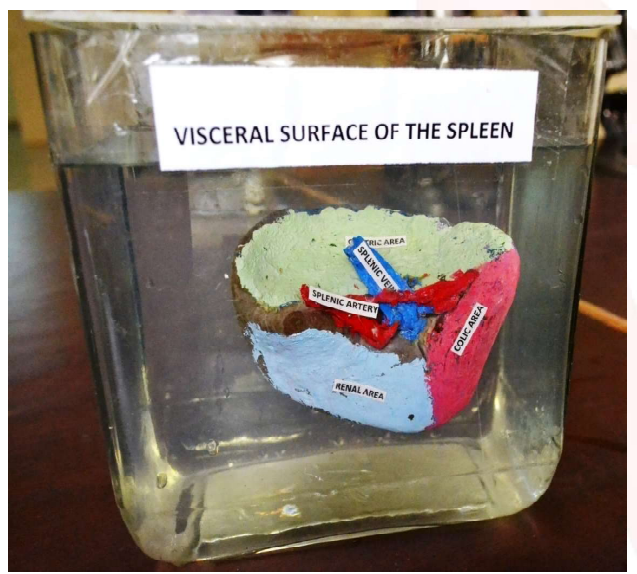

Fig. 2: Relations of postero-inferior surface of liver (direct labeling).

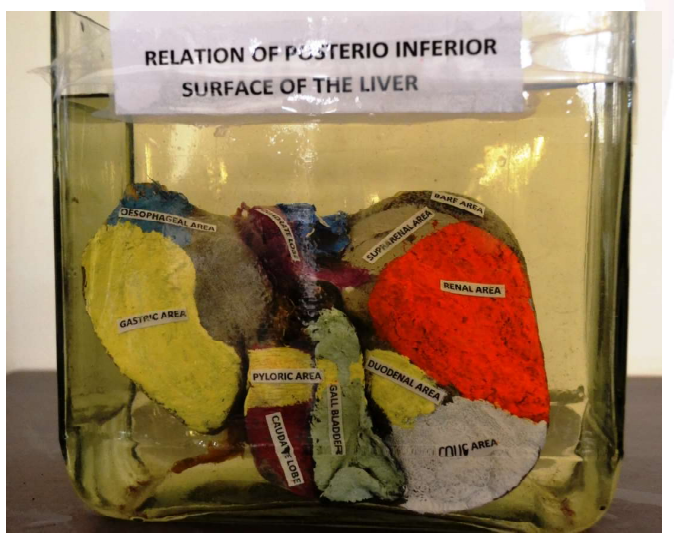

Fig. 3: Relations of posterior surface of right and left kidneys (color code labeling)

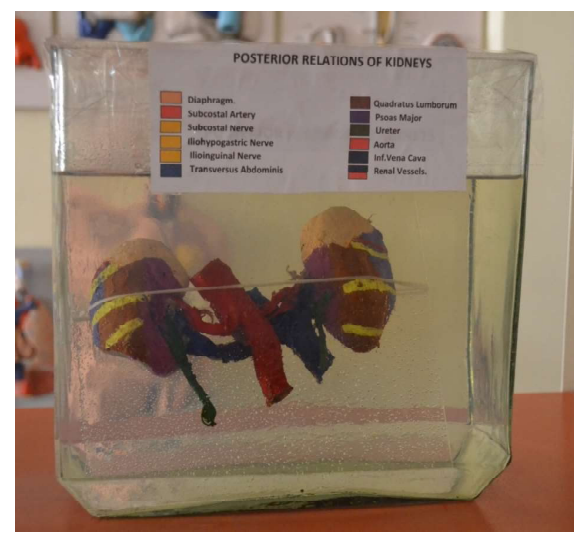

Fig. 4: Right side of face showing branches of facial nerve,facial artery and parotid duct ( color code labeling)

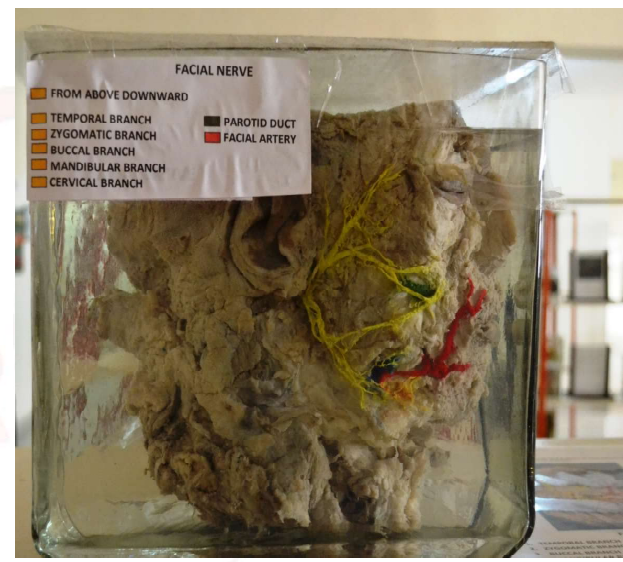

Fig. 5: Relations of anterior surface of kidneys (color code labeling).

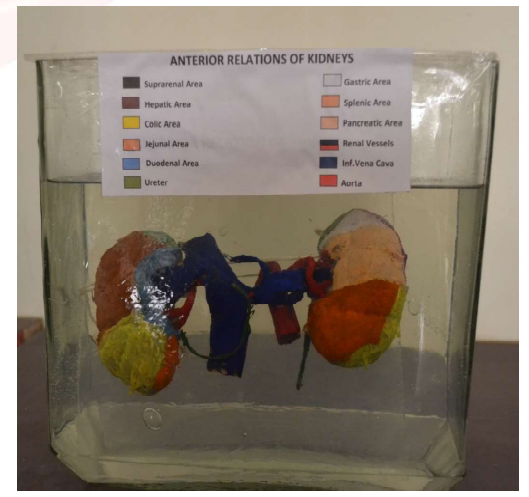

Fig. 6: Colored arteries and veins of heart (color code labeling).

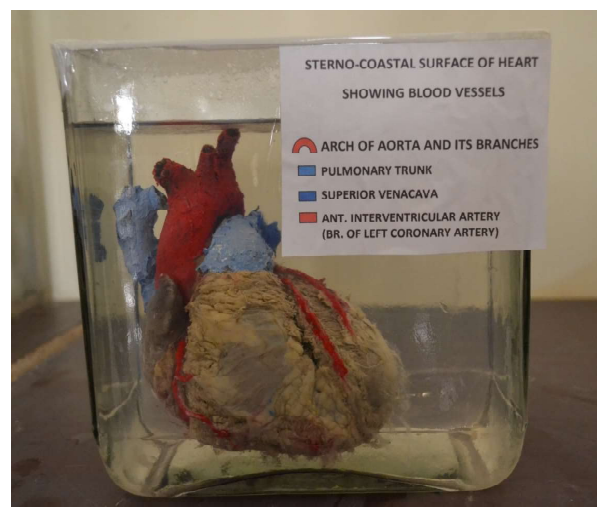




\section{RESULTS}

By this technique various important structures and impressions of related viscera were painted with anatomically correct colors. Colors evenly spread over the structures. The colored specimens were kept in formalin filled jars and have not shown any visible changes in color for the last two years. With this technique it became easier for the students to understand relations of various structures in the specimen. Layering colored specimens with a coat of clear nail polish adds shine to the color and prevents the running of the color into the mounting fluid. Nail paint increases the durability of the specimen and also prevents turbidity of the fluid necessitating its change. No leakage or mixing of colors is noticed till date. Moreover, materials used are non-toxic and easy to handle.

Direct labels applied on the specimens have not shown any change in formalin solution and are as new as they were on the first day of mounting.This proves not only the cost effectiveness of the products used but also make the monochromic specimens more attractive and lively.Thus it helps students in identification and understanding of relations of various structures in a specimen.

\section{DISCUSSION}

Colored anatomical specimens are very valuable in teaching students of medical science.Many workers used different techniques to color the specimen with or without Plastination (Tabl-1).

Table 1: Comparision of the materials used for coloring wet specimen.

\begin{tabular}{|c|c|c|c|}
\hline S. No. & Author & Year & Material Used \\
\hline $\mathbf{1}$ & Congdon ED [6] & 1932 & Albuminous paint \\
\hline $\mathbf{2}$ & Saunders [7] & 1944 & Lacquer \\
\hline $\mathbf{3}$ & Robert et al [8] & 1997 & Silicon \\
\hline $\mathbf{4}$ & Jain et al [9] & 2014 & $\begin{array}{c}\text { Camlin oil paint \& white } \\
\text { Enamel paints }\end{array}$ \\
\hline $\mathbf{5}$ & Prabhu et al [3] & 2015 & $\begin{array}{c}\text { Acrylic or poster paint,Nail } \\
\text { paint \& amyl acetate }\end{array}$ \\
\hline
\end{tabular}

Many workers used different techniques to color specimens. Congdon, E. D.[6] used albuminous paints to color the specimen. Intra-vascular injection of silicone, gelatin, latex or epoxy was used to highlight the vessels [10-15]. Saunders [7] demonstrated the use of lacquer for painting wet specimens. It was proved to be satisfa- ctory for larger vessels but inadequate for smaller tissues as the colors blurred and tended to run.

Robert et al[8] used silicon to color plastinated speci-mens. Although everything of the specimen is essential but the important parts dissected may be highlighted in wet specimen with the permanent colors.Jain and Babel[9] used camlin oil paints mixed with white enamel paint to color the specimens and kept these colored specimens in 10 percent formalin filled jar. They also used the same technique to color various structures of dry specimen [9].

Prabhu et al [3] used acrylic colors and commercially available nail polish with amyl acetate to color structures on wet specimen.Jain et al[9] and Prabhu et al[3] have reported no damage or fading of colors for a period of more than five years.

We combined the last two methods for a better output and durability. We used acrylic paints mixed with white enamel paint. After drying we added a coat of transparent nail paint which added to the durability and look of the specimens.The technique is convenient to perform and the colors donot fade in formalin with time. The colors are well adherent and evenly spread on the structures to be painted. By this technique arteries, nerves, veins, ligaments, impressions of the viscera can be colored which remain permanently in formalin filled glass jar. Also we used different methods to label the specimens.

LABELLING-The value of a museum specimen as an aid to teaching can't be measured simply on its appearance or the technical excellence of its mount.It must be clearly labeled which allows easy and rapid access to description of the specimen[16].Different methods of labeling as given by various authors are shown in Table 2 .

Table 2: Showing Different Methods of Labeling.

\begin{tabular}{|c|c|c|c|}
\hline S. No. & Author & Year & Labels Used \\
\hline 1 & Pulvertaft RJV [17] & 1950 & Old X-Rays \\
\hline 2 & Prabhu et al [3] & 2015 & Sheets (Direct \& Proxy) \\
\hline
\end{tabular}

In early days labels were made using old X-ray sheets by removing emulsion in hot water[17]. Prabhu et al[3] used computerized labels for direct and proxy labeling of the wet specimens. 
Well labeled specimen speak for itself. To achieve this we used computerized direct labels of required size and clear font, coated with clear nail paint fixed directly on twenty five colored specimens. The coat offered by clear nail polish prevents the leakage of the ink onto the specimen and into the fixating fluid. We also used color code labels for other specimens. For the latter simple white A-4 sheet was used .This sheet with color codes and names of the structures printed on it was pasted on the jar containing the specimen. Thereby long term preservation of the displayed specimens in the anatomy museum is ensured.

\section{CONCLUSION}

Good museum specimen are only obtained and preserved by care and planning and careful treatment after its removal. It is a better way of presentation of the specimens. Colors aids memory and make the monochromic specimens more beautiful and lively.

\section{Conflicts of Interests: None}

\section{REFERENCES}

[1]. Hannaway C, La Berge A.1998.Paris Medicine: Perspectives Past and Present, in Constructing Paris Medicine, eds. C. Hannaway and A. La Barge, Amsterdam, Rodopi. 1- 70.

[2]. Stelmackowich C. The Instructive Corpse. Dissec tion, Anatomical Specimen Illustration in early nineteenth century Medical Education, Spontaneous Generations: A journal for the History and Philosophical Science 2012;6(1):50-64.

[3]. Latha V. Prabhu, Mangala M. Pai, Divya Premchandran, Rajanigandha Vadgaonkar, Murlimanju B.V. A Novel Method For Coloring And Labeling Specimens In The Anatomy Museum. Int $J$ Anat Res 2015;3(2):1165-1167.
[4]. Toedt John, Koza Darrell, and Cleef-Toedt Kathleen Van. 2005. Chemical Composition Of Everyday Products. Greenwood Publishing Group p 49.

[5]. Tompsett DH 1956.Anatomical Techniques.E. \& S. Livingstone Ltd.Edinburgh \& London.p-59

[6]. Congdon, E. D. The use of albuminous paints in anatomical preparations. The Anatomical Records1932; 51(3):327-331.

[7]. Saunders M, Rice AH. A practical technique for preserving surgical and anatomical dissections. J Bone Joint Surg Am 1944;26:185-88.

[8]. Robert W. Henry, Larry Janick, and Carol Henry. Specimen Preparation for Silicone Plastination. Journal of the Inter-national Society for Plastination. 1997;12(1):13-17.

[9]. Lalit Kumar Jain, Hitesh Babel. Method of coloring wet specimen in anatomy. Int J Cur Res Rev 2014;6(22):20-23.

[10]. Tiedemann K, von Hagens G. The technique of heart plastination. Anat Rec. 1982;204: 295-299.

[11]. Von Hagens G. Heidelberg plastination folder: Collection of all technical leaflets for plastination. Anatomisches Institut 1, Universitat Heidelberg, Heidelberg, Germany,1985.

[12].Oostrom K. Plastination of the heart. J Int Soc Plastination 1987;1(2):12-19.

[13]. Oostrom K, von Hagens G. Plastination of the human placenta.J Int Soc Plastination 1988;2(1):1823.

[14]. Riepertinger A, Heuckendorf E. E20 color-injection and plastination of the brain. J Int Soc Plastination 1993;7(1):8-12.

[15]. Grondin G, Olry R. Vascular patterns of plastinated human hands with special reference to abnormalities of the arterial palmar arches. J Int Soc Plastination 1996;10:19-21.

[16]. Culling CFA1957. Handbook Of Histopatological Technque.Butterworth \& Co.Publishers Itd.London.p379

[17]. Pulvertaft R. J. V. Museum techniques: a review. J Clin Pathol 1950;3:11-23 doi:10.1136/jcp.3.1.1

How to cite this article:

Neelamjit Kaur, Rakesh Kumar Agarwal, Seema Khajuria, Harsh, Hemant Saini. TECHNIQUE FOR PRESERVING COLORED WET SPECIMEN IN ANATOMY MUSEUM. Int J Anat Res 2017;5(2.2):3824-3828. DOI: 10.16965/ijar.2017.192 